\title{
Investigating the drivers of the unprecedented Chernobyl Power Plant Wildfire in April 2020 and its effects on ${ }^{137} \mathrm{Cs}$ dispersal
}

\author{
Fiona Newman-Thacker ${ }^{1}$ (D) Laura Turnbull $^{1}$ (D)
}

Received: 27 November 2020 / Accepted: 24 June 2021 / Published online: 3 July 2021

(c) The Author(s) 2021

\begin{abstract}
In this study, we explore the conditions that led to the unprecedented wildfire that occurred in the Chernobyl Exclusion Zone in April 2020 and the effect of this fire on ${ }^{137} \mathrm{Cs}$ dispersal, as wildfires are important drivers of ${ }^{137} \mathrm{Cs}$ resuspension, with potentially harmful consequences for the receiving ecosystems. We characterised the historical wildfire record between 2000 and 2020 using the MCD64A1.006 MODIS Burned Area Monthly Global $500 \mathrm{~m}$ dataset and assessed the climatic conditions associated with these wildfire events using ERA5-Land reanalysis data. We also examined fire danger indices at the time of these wildfires. We then explored the widespread effects of the April 2020 wildfire on ${ }^{137}$ Cs resuspension and subsequent deposition using the NOAA-HYSPLIT model, concluding that the impacts of such resuspension on areas further afield were minimal. Results show that climatic conditions leading to severe wildfires are increasing, especially during March and April. High soil moisture, relative humidity and extreme temperature anomalies are associated with the largest wildfires on record, and fire risk indices at the time of the April 2020 fire were higher than for other large fires on record. We have estimated that $3854 \mathrm{GBq}$ of ${ }^{137} \mathrm{Cs}$ resuspended during the CPPF, with atmospheric transport dominant over Russia, Ukraine, Moldova and Kazakhstan. The observed increase in large wildfires will have implications for wildfire-driven soil erosion processes, which will further exacerbate the effects of atmospheric-driven ${ }^{137} \mathrm{Cs}$ redistribution.
\end{abstract}

Keywords Radionuclide dispersal · Climate and weather anomalies · Wildfire regime · Chernobyl Exclusion Zone

\section{Introduction}

Over recent years, there has been increasing concern surrounding the rise in wildfire frequency and extent within the Chernobyl Exclusion Zone (CEZ), largely due to the resuspension of radionuclides and their subsequent deposition in receiving ecosystems.

Fiona Newman-Thacker

Fiona.nt97@gmail.com

1 Department of Geography, Durham University, Durham, UK 
Several studies have quantified the impact of these wildfires on the resuspension of radionuclides, due to the potential risk that dispersal may pose to areas further afield (Hohl et al. 2012; Evangeliou et al. 2016; Ager et al. 2019). Radionuclides are present throughout the CEZ, originating from the 1986 nuclear disaster at the Chernobyl Nuclear Power Plant (ChNPP). The nuclear disaster dislocated the roof of the reactor, releasing a radioactive cloud which spread across the majority of Europe with varying intensities (Yankasova and Hannam 2013; Skrynyk et al. 2019). The CEZ, which covers around $2600 \mathrm{~km}^{2}$, was formed shortly after the disaster, due to the potentially lethal levels of contamination deposited in the area making it unsuitable for continued human habitation (Dusha-Gudym 2005; Hohl et al. 2012). Forests within the CEZ are largely unmanaged which, in combination with increasing forest dieback attributable to local climate change, increases the risk of particularly catastrophic fires (Evangeliou et al. 2015).

Wildfires pose a threat to areas downwind of contaminated soils, due to their potential to release radionuclides stored in vegetation and soils, and the subsequent displacement by wind. Released during the Chernobyl disaster, caesium ${ }^{137}\left({ }^{137} \mathrm{Cs}\right)$ and strontium ${ }^{90}\left({ }^{90} \mathrm{Sr}\right)$ are the two most dangerous radionuclides present within the CEZ (Evangeliou et al. 2014). Notably, there is proportionally more ${ }^{137} \mathrm{Cs}$ than ${ }^{90} \mathrm{Sr}$ within the top $5 \mathrm{~cm}$ of soil across the CEZ, making it more likely to be displaced by a wildfire event (Yablokov et al. 2009; Evangeliou et al. 2014).

In April 2020, $365 \mathrm{~km}^{2}$ of the CEZ burned, and of this fire complex, the Chernobyl Power Plant Wildfire (CPPF), which burned between 8 April and 24 April, was particularly notable, due to its proximity to the ChNPP and the fact that it became the largest singular fire on record within the CEZ, covering $169 \mathrm{~km}^{2}$ (Fig. 1). The area of the CPPF was considered previously to be at relatively low risk of wildfire, but this area is also highly contaminated with radionuclides (Ager et al. 2019; Hohl et al. 2012). The CPPF was triggered by an act of arson (Alimov 2020; Chornokondratenko and Marrow 2020). Prior to the CPPF, the largest fire on record within the CEZ occurred in April $2015\left(109 \mathrm{~km}^{2}\right)$ and attracted attention due to its extreme size (Evangeliou et al. 2016).

Wildfire management within the CEZ has changed little over the past years, and therefore, it is likely the ongoing changes in the area's wildfire regime have been influenced by regional variations in climate. Within the CEZ, high temperatures and low precipitation levels have been linked previously to significant fires (Evangeliou et al. 2015; Ager et al. 2019). Drier soils and increased wind speed have been linked to increased flammability and fire spread (Krueger et al. 2016; Chaparro et al. 2016; Sungmin et al. 2020). Both longand short-term weather trends are intertwined with wildfire risk determined by longer-term climatic conditions and are major factors in determining fire characteristics (Balabukh and Malystka 2017). Longer-term antecedent conditions in the weeks and months preceding a wildfire event are often overlooked, despite fuel moisture and productivity levels being interlinked with these antecedent conditions (Crimmins and Comrie 2004). Higher temperatures and longer drought-like conditions in the months preceding an event can decrease soil moisture content and produce landscape conditions which positively affect fuel continuity and potential fire spread (Evangeliou et al. 2015). Acute conditions are also important for establishing the impact of climatic conditions on wildfire events. In particular, wind speed has been shown to have significant consequences for wildfire spread, and high winds have been stated to have occurred in association with the 2020 Chernobyl wildfires (Roth 2020; Ager et al. 2019).

The aim of this study is to determine why, in a relatively "low risk" area, the CPPF burned such a large area, and evaluate the severity of the burn, alongside the impact 

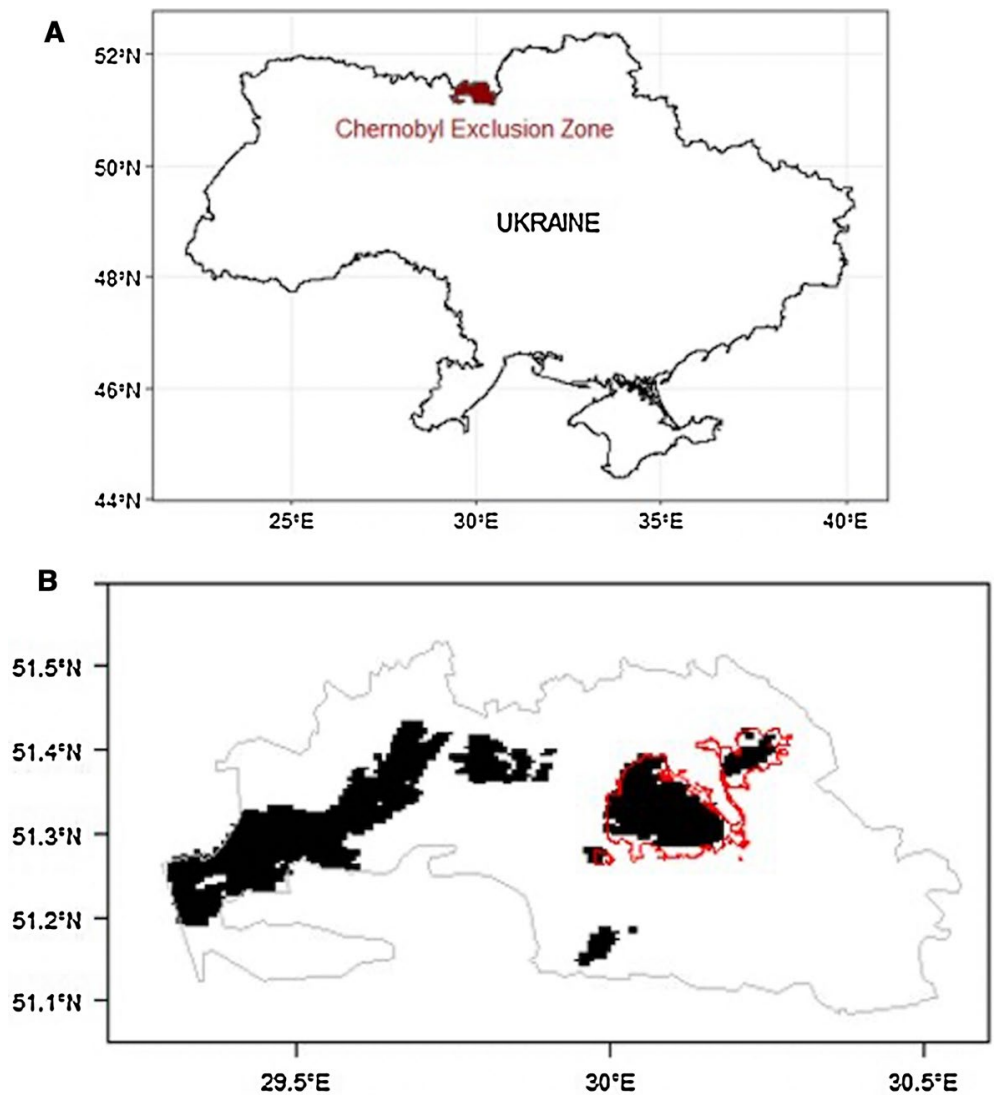

Fig. 1 a The location of the Chernobyl Exclusion Zone (CEZ) within Ukraine, and b the distribution of fires in April 2020 (mapped from the MODIS MCD64A1 fire product) shown in black, within the Chernobyl Exclusion Zone (CEZ), shown in grey. The perimeter of the Chernobyl Power Plant Wildfire (CPPF) is shown in red

of the atmospheric dispersal of ${ }^{137} \mathrm{Cs}$ from the wildfire event. To achieve this aim, we answer the following questions:

1. What is the historical wildfire regime in the CEZ and has it changed between 2000 and 2020 ?

2. How have the climatic drivers of wildfire changed over the same period?

3. To what extent did climatic conditions drive the large size of the CPPF?

4. What were the main impacts of this fire, in terms of burn severity, and the resulting atmospheric dispersal of ${ }^{137} \mathrm{Cs}$ and its consequent re-deposition? 


\section{Methods}

To characterise the historical wildfire regime, we extracted the MCD64A1.006 MODIS Burned Area Monthly Global 500 m dataset using the Google Earth Engine (GEE) cloud processor, covering a timespan from 2000 to 2020 . We then calculated monthly total burn area within the CEZ in R using the raster package (Hijmans and van Etten 2012).

We analysed how the climatic drivers of wildfire have changed between 2000 and 2020 using ERA5-Land reanalysis monthly data (Copernicus Climate Change Service Climate Data Store 2020), at $\sim 9 \mathrm{~km}$ resolution. We analysed rainfall, temperature (at $2 \mathrm{~m}$ ), relative humidity, wind speed (at $10 \mathrm{~m}$ ) and surface soil moisture (0-70 $\mathrm{mm}$ soil depth). We calculated anomalies for these variables relative to the 1981-2010 reference period. We focussed our soil moisture analysis on the uppermost soil layer, as this has the greatest influence on the overall flammability of the area (Benscoter et al. 2011). We determined relative humidity $(R H, \%)$ based on 2-m temperature $\left(T,{ }^{\circ} \mathrm{C}\right)$ and dew point temperature $\left(T_{\mathrm{d}},{ }^{\circ} \mathrm{C}\right)$ using the August-Roche-Magnus approximation:

$$
\mathrm{RH}=100 \frac{\left(\exp \left(\frac{17.625 T_{\mathrm{d}}}{243.04 T_{\mathrm{d}}}\right)\right.}{\left(\exp \left(\frac{17.625 T}{243.04 T}\right)\right.}
$$

To determine the extent to which weather preceding the CPPF and at the time of outbreak contributed to the large area burned, we analysed the fire risk indices which indicate the level of fire risk and the potential intensity of fire. We used the Canadian Fire Weather Danger Rating System (CFFDRS) (Van Wagner 1987), which is the most widely used system of assessing weather-related fire risk worldwide. We used the CFFDRS historical data product (Copernicus Climate Change Service Climate Data Store 2020) which is calculated using ERA reanalysis data. We focused our analysis on the Fire Weather Index (FWI) which is an integrated measure of potential fire intensity and is used as a general indicator of fire danger, the Fine Fuel Moisture Code (FFMC) which represents the moisture of forest litter fuels, and the Drought Code (DC) which is an indicator of the moisture content in deep compact organic layers $(\sim 10-20 \mathrm{~cm}$ deep) that have a slow drying rate. To put the CPPF into its historical context, we undertook this analysis for all fires greater than $1 \mathrm{~km}^{2}$ between 2000 and 2020. To help interpret our analysis of fire risk indices, we also analysed daily weather anomalies calculated using ERA5-Land reanalysis daily data (Copernicus Climate Change Service Climate Data Store 2020) for the day of fire outbreak. To determine the extent to which weather conditions exacerbated (and eventually halted) the spread of the CPPF, we explored daily weather variables for the duration of the CPPF and in the days pre- and post-fire.

We used the differenced Normalised Burn Ratio (dNBR; Eq. 2) to determine burn severity of the CPPF (for the CPPF fire perimeter from the Copernicus Emergency management Service 2020), calculated using GEE (Soverel et al. 2010).

$$
\mathrm{dNBR}=\text { PreFireNBR }- \text { PostFireNBR }
$$

We related the dNBR values to the USGS burn severity levels (Key and Benson 2006; Supp. Info S2).

To evaluate radionuclide dispersal resulting from the CPPF, we determined the prefire concentrations of ${ }^{137} \mathrm{Cs}$ and then estimated the resuspension of ${ }^{137} \mathrm{Cs}$ during the fire, followed by modelling its subsequent atmospheric dispersal using the NOAA HYSPLIT 
(Hybrid Single Particle Lagrangian Integrated Trajectory) model (Stein et al. 2015; Rolph et al. 2017). To determine the spatial variation of soil ${ }^{137} \mathrm{Cs}$ prior to the CPPF in 2019, we applied the approach used by Ager et al (2019). Specifically, we used a point-based dataset of soil of ${ }^{137} \mathrm{Cs}$ from 1995 (Kashparov et al. 2017) and then used these 1995 levels to estimate 2019 levels using a half-life of 17 years (Paller et al. 2014; Eq. 3):

$$
A=A_{0} *(0.5)^{(\mathrm{DP}-\mathrm{Te})}
$$

where $A$ is 2019 contamination and $A_{0}$ is 1995 deposition values, DP (the number of years since the inventory was taken) is 24 years (1995-2019) mapping, and Te (the effective half-live) is 17 years (as suggested by Paller et al. 2014). We used the empirical Bayesian kriging (EBK) interpolation method within ArcMap 10.3.1 to estimate soil ${ }^{137} \mathrm{Cs}$ for 2019 across the area affected by the CPPF. We used the EBK method because of its high levels of accuracy and its ability to outperform other methods, such as the empirical posterior distribution method (Krivoruchko and Gribov 2020; Samsanova et al. 2017).

We determined the overall amount of ${ }^{137} \mathrm{Cs}$ released from the CPPF based on the concentration of ${ }^{137} \mathrm{Cs}$ within the top layer of soil, following the approach of Evangeliou et al (2016), where $20 \%$ of labile soil ${ }^{137}$ Cs (which we calculated for the CPPF zone using Eq. 2) is emitted to the atmosphere during a wildfire (Paliouris et al. 1995; Amiro et al. 1996; Yoschenko et al. 2006; Evangeliou et al. 2016). Recently, Evangeliou and Eckhardt (2020) used a ${ }^{137} \mathrm{Cs}$ emission factor of $1.2 \%$-informed by laboratory experiments by Hao (2018), which concluded that between 1 and $2.5 \%$ of the total caesium in pine needles was emitted during a fire. Therefore, our assumption that $20 \%$ of labile soil ${ }^{137} \mathrm{Cs}$ is emitted during a fire is likely to represent an upper limit on this environmental hazard. We did not explicitly consider ${ }^{137} \mathrm{Cs}$ emitted from vegetation due to a paucity of empirical data and considerable uncertainty in estimating original ${ }^{137} \mathrm{Cs}$ concentrations within different vegetative species (Paatero et al. 2009; Yoschenko et al. 2006; Bondar et al. 2014).

We modelled the resuspension of the radionuclide ${ }^{137} \mathrm{Cs}$ using the Lagrangian atmospheric dispersal modelling system HYSPLIT Desktop Version 4.2.0. We ran the model for the period 8 April-18 April. Our parameterisation of HYSPLIT is given in the supplementary information. An important parameter in HYSPLIT is the height of the wildfire smoke plume, as this is extremely influential in determining the dispersal of radionuclides (Brown et al. 2011; Evangeliou et al. 2015; Nelson et al. 2008, 2013). Whilst the CPPF was not completely eradicated until the 24 April, its smouldering status past the 18 meant further smoke plume heights could not be retrieved (Reevel 2020; Chornokondratenko and Marrow 2020). We extracted the height of the wildfire smoke plume from the 2020 Copernicus Atmospheric Monitoring Service Information Global Fire Assimilation (CAMS GFAS 2020) database, which uses a one-dimensional plume rise model (PRM) (Freitas et al. 2007) to quantify smoke plume top and bottom height (Remy et al. 2017; Kaiser et al. 2012). We then processed the dataset in R, to extract smoke plume values for the exact location of the CPPF. HYSPLIT is parameterised using single values for the base and top heights of the smoke plume, for the entire duration of the fire, and does not permit use of time-varying values. We therefore used the lowest smoke plume value of $200 \mathrm{~m}$ and highest value of $2418 \mathrm{~m}$ to define the vertical height of the suspended ${ }^{137} \mathrm{Cs}$, which thus represents the maximum possible dispersal of ${ }^{137}$ Cs. We ran the HYSPLIT model using an $80^{\circ}$ extent to cover the entirety of Europe, western Asia, and northern Africa and the Middle East. We ran HYSPLIT using the GDAS $1^{\circ}$ meteorological dataset, because its temporal coverage extended to April 2020. 


\section{Results}

\subsection{The wildfire regime between 2000 and 2020}

Most of the fires within the CEZ are small (Fig. 2a). Only 9\% of the fires between 2000 and 2020 burned an area greater than $100 \mathrm{~km}^{2}$. The CPPF is by far the largest discrete fire event to have occurred during this period. The dominant wildfire season in the CEZ occurs between February and April (Fig. 2b). April is the principal wildfire month in terms of total burn area, although this pattern is driven entirely by the CPPF in April 2020, as prior to the CPPF, March was the dominant month. The CPPF burned 365.6 $\mathrm{km}^{2}$, which exceeded the previous largest fire on record (the 2015 wildfires which occurred between February and April 2015) by $68.3 \mathrm{~km}^{2}$. Over this period there is a significant upward trend in burn area $\left(R^{2}=0.19, p=0.0695\right)$ (Fig. 2c).

Prior to the CPPF, between 2000 and 2019, the western part of the CEZ had higher burn frequency, with some areas burning up to seven times during this 20-year period (Fig. 3a). The south-westernmost corner of the CPPF has partially burnt up to three times between 2000 and 2019 although the rest of area has no history of wildfires over the last 20 years (Fig. 3b).

\subsection{Climate and conditions surrounding wildfires within the CEZ}

Due to the importance of climatic conditions on wildfire risk, we analysed how climatic anomalies have changed between 2000 and 2020. Between 2000 and 2020 analysis of monthly climatic variables shows a significant decrease in soil moisture and relative humidity (Fig. 4, Table 1). We also analysed trends in climatic variables for the dominant wildfire months: February, March and April. There are no significant changes in any of the climatic variables investigated for February. There is a significant increase in temperature for March and a significant decrease in soil moisture, relative humidity and wind speed. April also shows a significant decrease in soil moisture and relative humidity, alongside precipitation. Wind speed also sees a significant increase in April.

\subsection{Conditions at the time of wildfire outbreak}

The FWI, FFMC and DC at the start of the CPPF were some of the highest values on record (Fig. 5a). Other fires with high FWI values did not result in large burn areas. Upon closer inspection of the weather variables that are used to derive the fire risk indices (Fig. 5b), it is clear that the particularly large fires all had particularly high temperature anomalies, whilst the CPPF was outstandingly high. Although the 2015 fires (which prior to the CPPF were the largest fires on record) had slightly elevated FFMC, and moderately elevated DC, the overall fire risk, as indicated by the FWI, was much lower than for the CPPF. The much higher DC at the start of the CPPF indicates the pronounced dry conditions at greater depths in the compact organic layers. Analysis of weather anomalies at the start of each wildfire shows a consistent pattern of positive temperature anomalies (Fig. 5b). The weather conditions at the start of the CPPF were outstanding inasmuch as temperature anomalies were the highest recorded at the start of 
Fig. 2 a Histogram of wildfire burn area between 2000 and 2020; b total area burned per month between 2000 and 2020 , by fire size; $\mathbf{c}$ wildfire burn area within the CEZ $\left(\mathrm{km}^{2}\right)$ by year, from January 2000 to April 2020 showing linear regression $\left(R^{2}=0.19, p=0.0695\right)$ and the 0.95 confidence interval
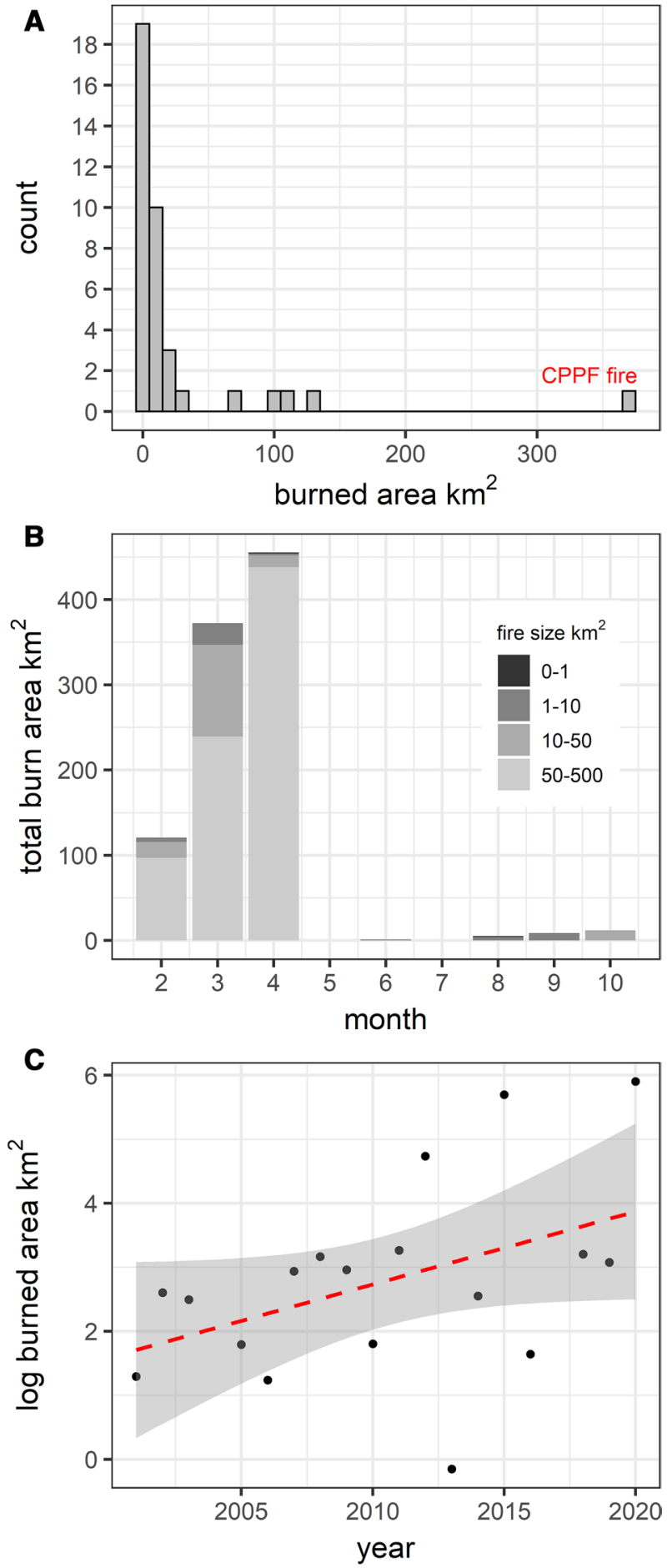


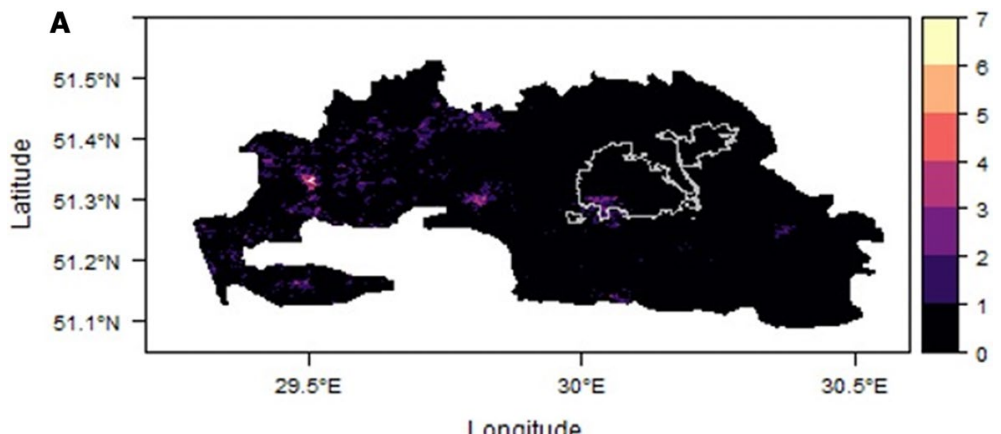

B

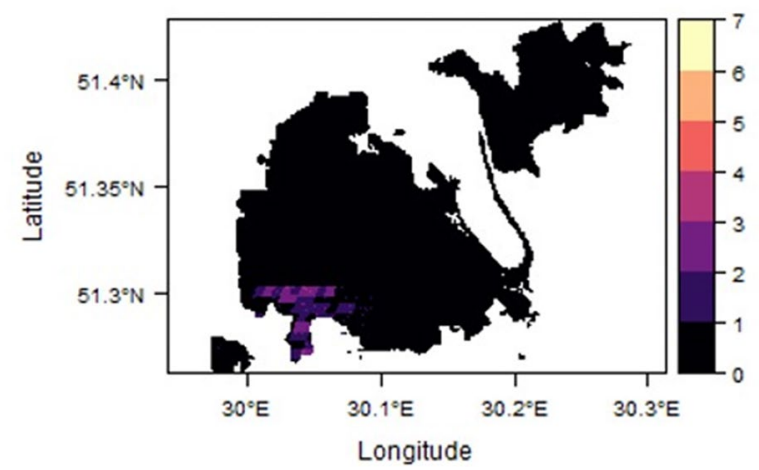

Fig. 3 a Number of fires between January 2000 and December 2019 within the CEZ derived from the MODIS burn product. The perimeter of the CPPF fire in April 2020 is also shown; $\mathbf{b}$ the MODIS burn data for the same temporal length, for the area contained within the CPPF perimeter

all wildfires on record (temperature anomaly of $12{ }^{\circ} \mathrm{C}$ ), and soil moisture anomalies and relative humidity anomalies were also particularly low.

Actual weather conditions throughout the duration of the CPPF are shown in Fig. 6A-I. Temperature anomalies were high in the days preceding the fire and were high for most of the duration of the CPPF. Precipitation, soil moisture and relative humidity anomalies were negative for the full duration of the fire. The rainfall in mid-April within the CEZ was instrumental in reducing the fire intensity and fire spread, and the fires ended towards the end of April. Wind speed was not consistently anomalously high; however, some high values were recorded during the middle and towards the end of the fire.

\subsection{Impacts of the CPPF}

The most severe burning occurred in the centre of the CPPF and to the north-east (Fig. 7a), burned areas with moderate-high and high severity occurred in close proximity to the Chernobyl Power Plant alongside the town of Prip'yat (Fig. 7b). The resulting smoke plume from the CPPF reached an upper height $\sim 2500 \mathrm{~m}$ nearer the start of the fire, decreasing to $2000 \mathrm{~m}$ in the latter stages (Fig. 8). 
Based on the distribution of soil ${ }^{137} \mathrm{Cs}$ within the area burnt, we have estimated that $3854 \mathrm{GBq}$ of ${ }^{137} \mathrm{Cs}$ was resuspended during the CPPF. The resulting atmospheric concentrations of ${ }^{137} \mathrm{Cs}$ changed throughout the lifespan of the wildfire as a result of prevailing atmospheric conditions. The ${ }^{137} \mathrm{Cs}$ resuspended during the CPPF originally dispersed south, before spreading east and north-east (Fig. 9).

By 15 April, concentrations of ${ }^{137} \mathrm{Cs}$ had spread far enough north to be within the Arctic Circle, albeit in small quantities. The southernmost extent of ${ }^{137} \mathrm{Cs}$ dispersal was northern Africa, with Egypt being predominantly affected. Atmospheric transport was dominant over western Russia, Ukraine, Moldova and Kazakhstan with atmospheric concentrations greater than $0.000001 \mathrm{~Bq} \mathrm{~m}^{3}$. As a result of this pattern of atmospheric dispersal of ${ }^{137} \mathrm{Cs}$, most areas downwind of the CPPF experienced deposition between 0.0001 and $0.01 \mathrm{~Bq}$ $\mathrm{m}^{2}$ (Fig. 9). The area in the immediate vicinity of the CEZ and area to the south experienced deposition of ${ }^{137} \mathrm{Cs}$ in concentrations greater than $1 \mathrm{~Bq} \mathrm{~m}^{2}$ and as high as $10 \mathrm{~Bq} \mathrm{~m}^{2}$ (Fig. 10).

\section{Discussion}

The CPPF is the largest singular wildfire that has occurred in the CEZ since the area was established, and it occurred in a location not previously established as high risk. However, an absence of previous large fires in this area, as indicated in Fig. 2a, will have led to greater fuel accumulation, and this may have predisposed the area to the unprecedented wildfire experienced in 2020 (Kauffman 2004; Keeley et al. 2004; Ager et al. 2019). In a comprehensive study of wildfire risk in the CEZ, Ager et al. (2019) estimated that the fire size potential in the area of the CPPF was $3.25 \mathrm{~km}^{2}$, which is considerably smaller than the observed burned area of $169 \mathrm{~km}^{2}$. Thus, it is clear that the assimilation of information on the historical wildfire regime, climatic conditions, vegetation properties, forest management regime, and modelled ignition probability, fire burn probability and fire size potential simply had not signalled that such a large wildfire could have occurred in this area. The significant increase in burn size area over the last 20 years, as shown in Fig. 2c, supports other conclusions within the literature that larger wildfires are becoming more common within the CEZ (Evangeliou et al. 2014; Ager et al. 2019) and that this trend is likely to continue when considering the persistent changes in climate in this region during the dominant wildfire season (Fig. 4).

Progressive warming and drying of both surface and deep soil layers throughout March and April is highly conducive for the production of extremely flammable vegetation. Near-surface soil-moisture deficits in particular increase sensible heating, which results in warmer surface air temperatures and increased evaporative demand, amplifying the conditions that make the environment more susceptible to wildfire (Westerling et al. 2006; Holden et al. 2018; Sungmin et al. 2020). Surface moisture and temperature anomalies have been significantly increasing across these already wildfire-prone months (Fig. 4). If this trend continues, it is likely the area will experience larger wildfires due to the increased flammability of fuel stores. Wind speed, which drives the spread of fire, increased significantly singularly within April across the 21-year period (Fig. 4). This suggests that April is potentially becoming more important in terms of consistent cooccurrence of favourable conditions for wildfire ignition and spread. Long-term climatic conditions have significant implications for wildfire size and duration, with our results 
Fig. 4 Climatic anomalies (relative to the 1981-2010 baseline period) for temperature, precipitation, surface soil moisture $(0-70 \mathrm{~mm})$, wind speed and relative humidity for the CEZ, from January 2000 to April 2020. Data for all months across all years are shown in grey, whilst data for the dominant wildfire months of February, March and April are shown in red, blue and green, respectively. Linear trendlines and 95\% confidence intervals are shown for each dataset (annual and for February, March and April). Corresponding statistics of the linear regression are given in Table 1

indicating that the changes occurring within the CEZ over the last 21 years are increasing the areas susceptibility to large wildfire events.

Conditions in the months prior to the CPPF fire in particular, when examined using the FWI, the FFMC and DC, indicate that the area was climatically ripe for a wildfire event, with the FWI and DC values being some of the highest on record (Fig. 5). These results suggest that the chosen indices could be used in future to evaluate the predisposition of the CEZ to a large wildfire event at a particular point in time. Consequently, producing these indices in real time may help in highlighting when certain management strategies, such as the creation of fuel breaks, would be appropriate. Our analysis also indicates that temperature anomalies may be the most significant factor within the FWI, as these high-temperature anomalies consistently coincide with the largest wildfires. Extreme temperatures directly impact soil moisture and relative humidity, allowing fire spread to be much greater (Balabukh and Malytska 2017). These findings are corroborated by previous research, concluding that high temperatures predispose the CEZ to large wildfire events (Borsuk and Zibstev 2013; Balabukh and Malytska 2017). As temperatures continue to increase, it is reasonable to assume that the trend of increasing wildfire burn area will continue, with more frequent "unprecedented" wildfire events. What is clear is that without taking into account the effects of extreme climatic anomalies on ecosystem properties, wildfire risk modelling systems, such as the one developed in Ager et al (2019), are unable to predict the likelihood of wildfires such as the CPPF occurring.

The analysis of very short-term weather prior, during and straight after the CPPF (Fig. 6) indicates that before the initiation of the fire, temperature, relative humidity and soil moisture variable reported anomalous values. These results are as expected when considering the high FWI and DC values explored earlier and also support the conclusion that anomalous climatic variables predispose the area to wildfire events. Anomalously, high wind speeds were recorded during several days of the CPPF's duration-however these are not consistent (Fig. 6f). Whilst these high winds are likely to have contributed to the rapid fire spread, their inconsistency suggests they may not have been the most influential factor in the substantial spread of the CPPF. Further research could be undertaken here to quantify the importance of individual short-term climatic variables on fire size.

From a management perspective, our results are useful inasmuch as they highlight the influence of climatic anomalies on the potential wildfire size, whereby it appears extreme temperature and soil moisture anomalies are consistently linked to large wildfires. Continuation of these severe anomalies is likely to normalise conditions such as enhanced fuel aridity, where "unprecedented" fires such as the CPPF are more likely to occur. Other studies have also found that anthropogenic climate change will lead to a rise in future fire activity within the CEZ, as long as fuels are not limited (Evangeliou et al. 2015; Abatzoglou and Williams 2016; Balabukh and Malystka 2017). Furthermore, our results suggest that the CFFDRWS could be used as a monitoring system and as a predictor surrounding the potential for large wildfire events, as the CPPF had some of the highest FWI and DC values on record. 

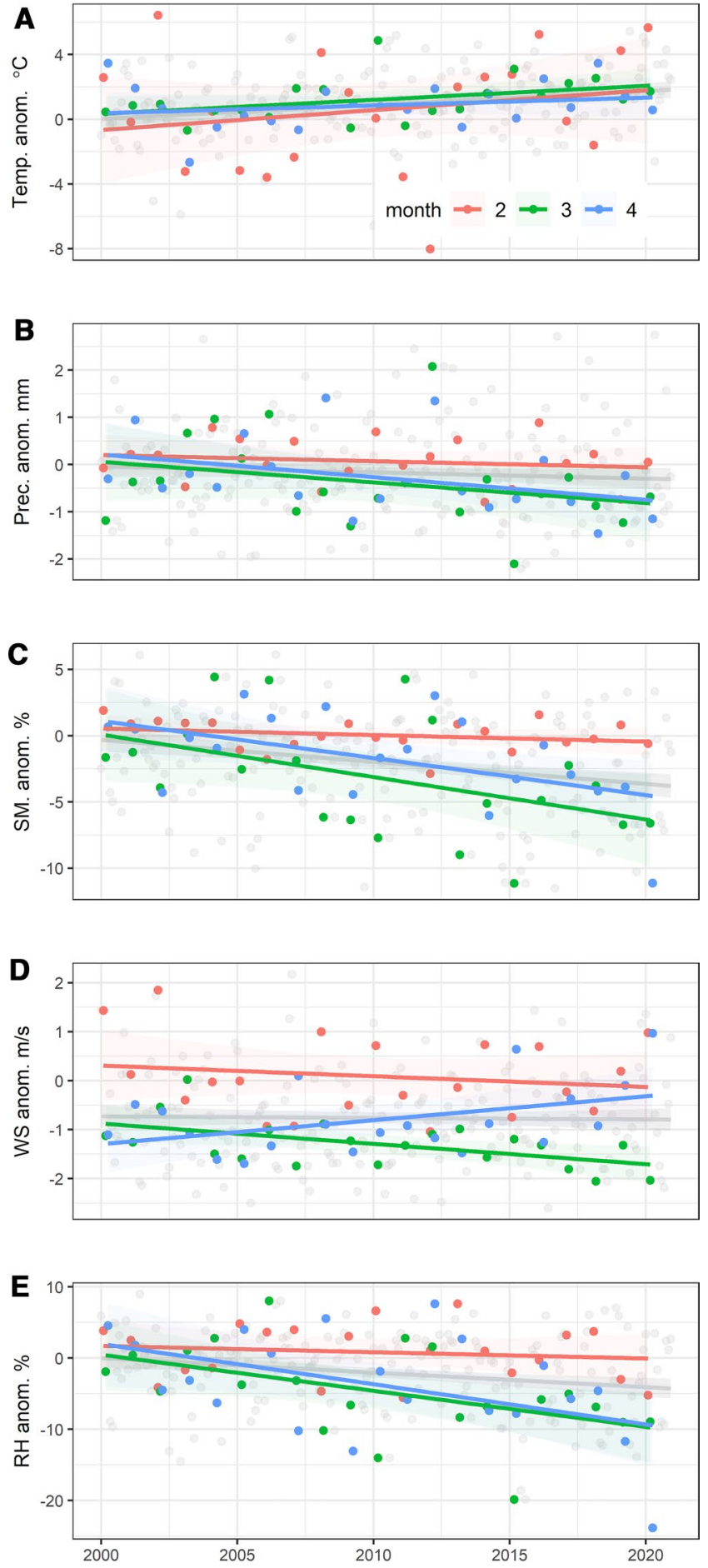
Table 1 Regression coefficients for climatic anomalies (temperature in ${ }^{\circ} \mathrm{C}$, precipitation in $\mathrm{mm}$, soil moisture in $\%$, wind speed in $\mathrm{m} / \mathrm{s}$ and relative humidity in \%) shown in Fig. 4

\begin{tabular}{lcclc}
\hline Variable & All months & Feb & March & \multicolumn{1}{l}{ April } \\
\hline Temp & 0.0002 & 0.1229 & $\mathbf{0 . 0 8 6 8 4}$ & 0.0483 \\
Prec & 0.0000 & -0.01302 & -0.04358 & $\mathbf{- 0 . 0 4 8 0 1}$ \\
SM & $\mathbf{- 0 . 0 0 0 5}$ & -0.04915 & $\mathbf{- 0 . 3 1 9 9}$ & $\mathbf{- 0 . 0 2 7 9 6}$ \\
WS & 0.0000 & -0.02175 & $\mathbf{- 0 . 0 4 1 4 9}$ & $\mathbf{0 . 0 4 8 8 0}$ \\
RH & $\mathbf{- 0 . 0 0 0 6}$ & -0.8838 & $\mathbf{- 0 . 5 0 6 6}$ & $\mathbf{- 0 . 5 6 4 1}$
\end{tabular}

Significant trends where $p<0.05$ are shown in bold
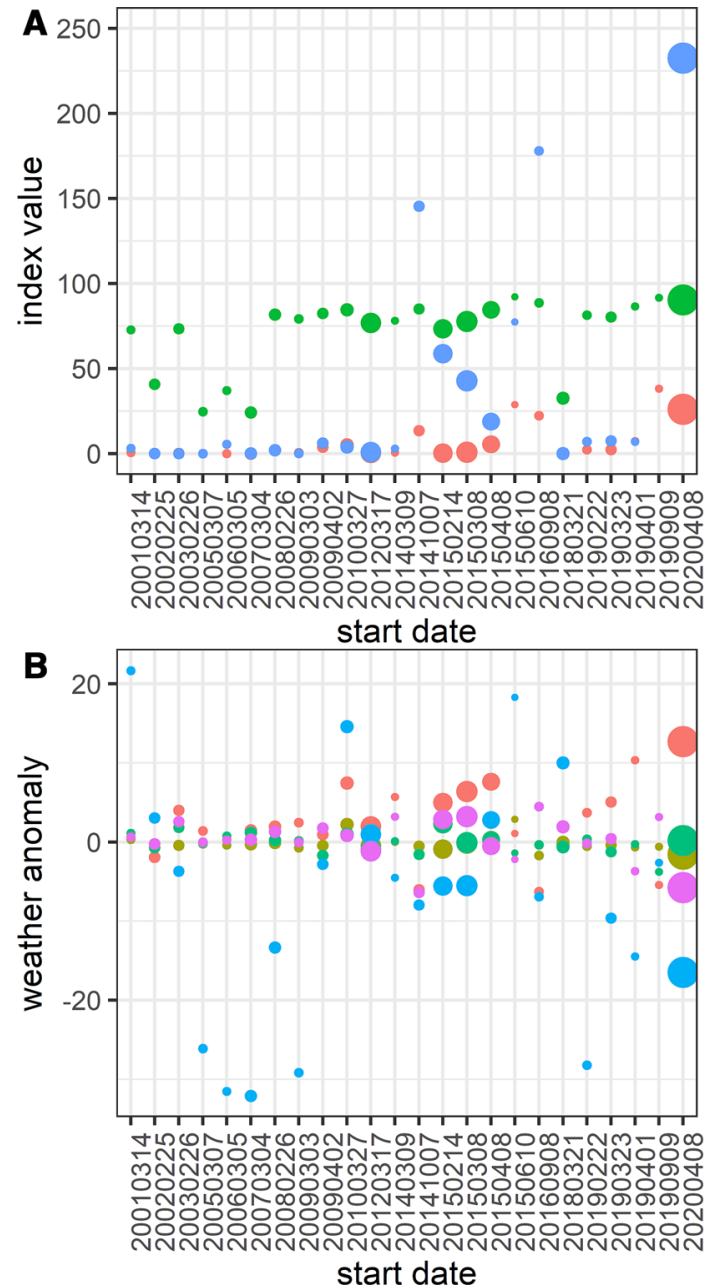

burned area $\mathrm{km}^{2}$

- 100

200

300

index

- FWI

- FFMC

- DC

\section{burned area $\mathrm{km}^{2}$}

- 100

- 200

- 300

\section{weather anomaly}

- TEMP

- PREC

- WS

- $\mathrm{RH}$

- SM

Fig. 5 a FWI (fire weather index), FFMC (fine fuel moisture code) and DC (drought condition) at time of fire outbreak and $\mathbf{b}$ climatic anomalies at time of fire outbreak (temperature (TEMP) in ${ }^{\circ} \mathrm{C}$, precipitation (PREC) in $\mathrm{mm}$, soil moisture (SM) in \%, wind speed (WS) in $\mathrm{m} / \mathrm{s}$ and relative humidity (RH) in \%. In both plots points are scaled by wildfire size 

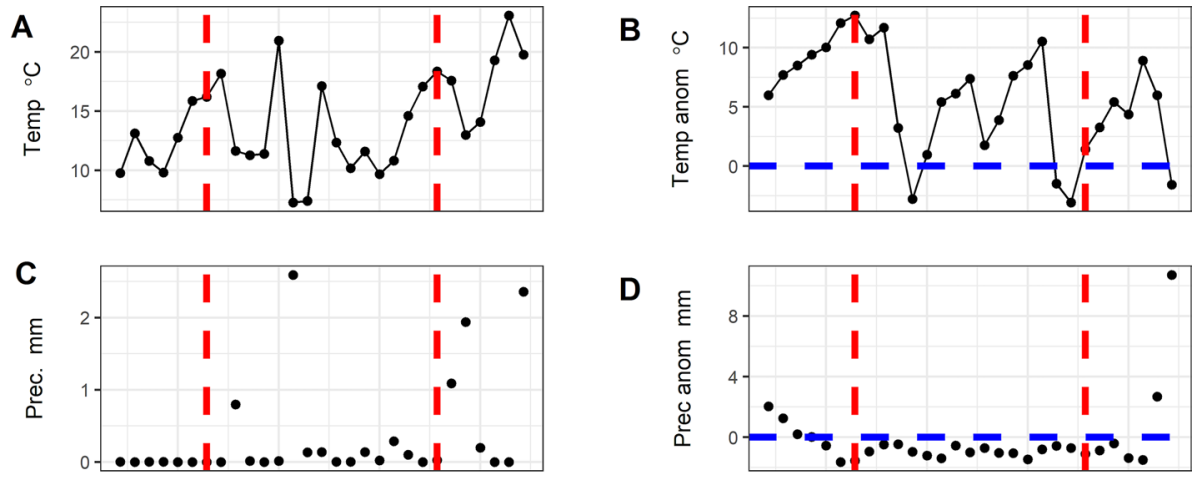

D
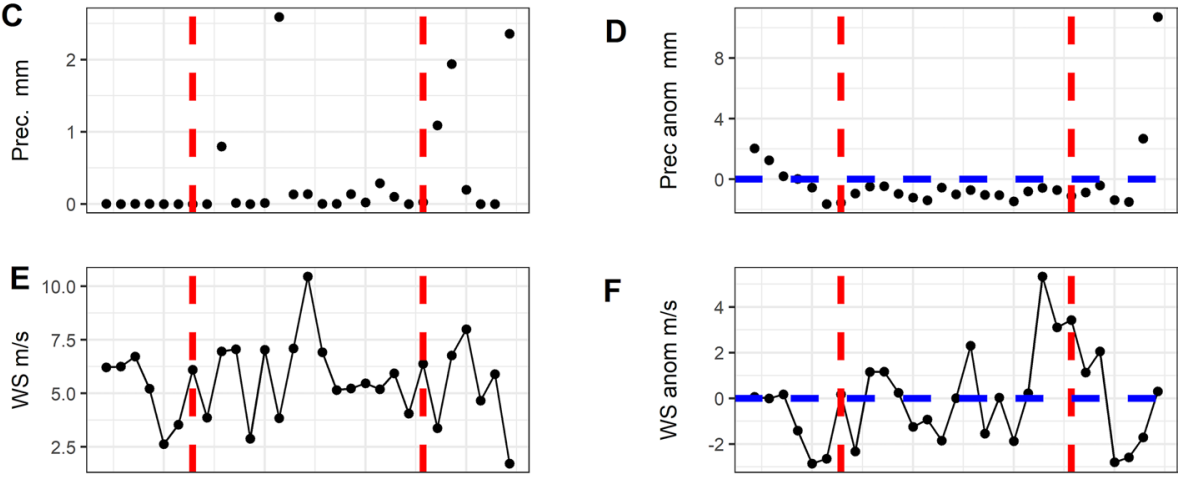

$\mathbf{F}$
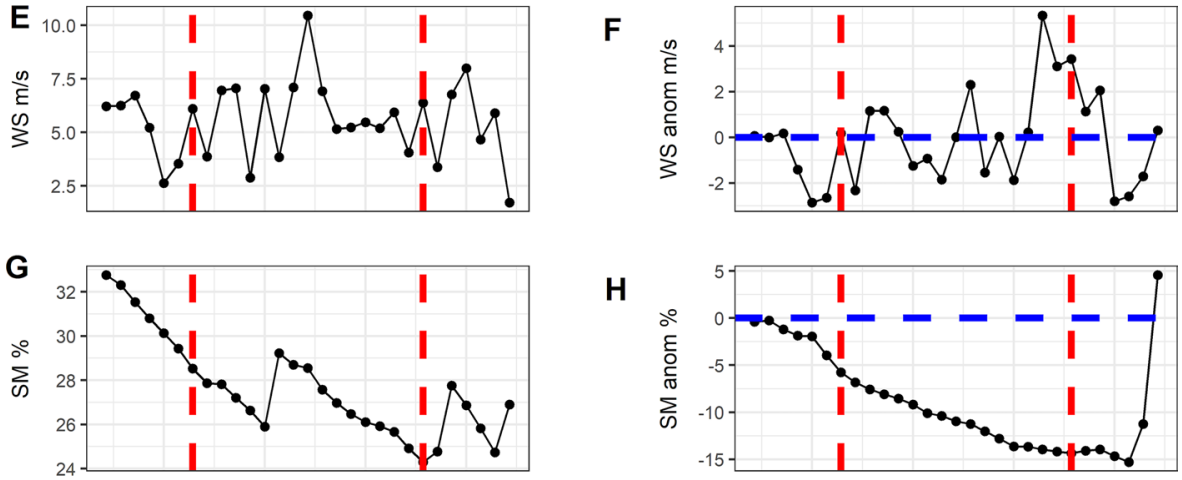

H
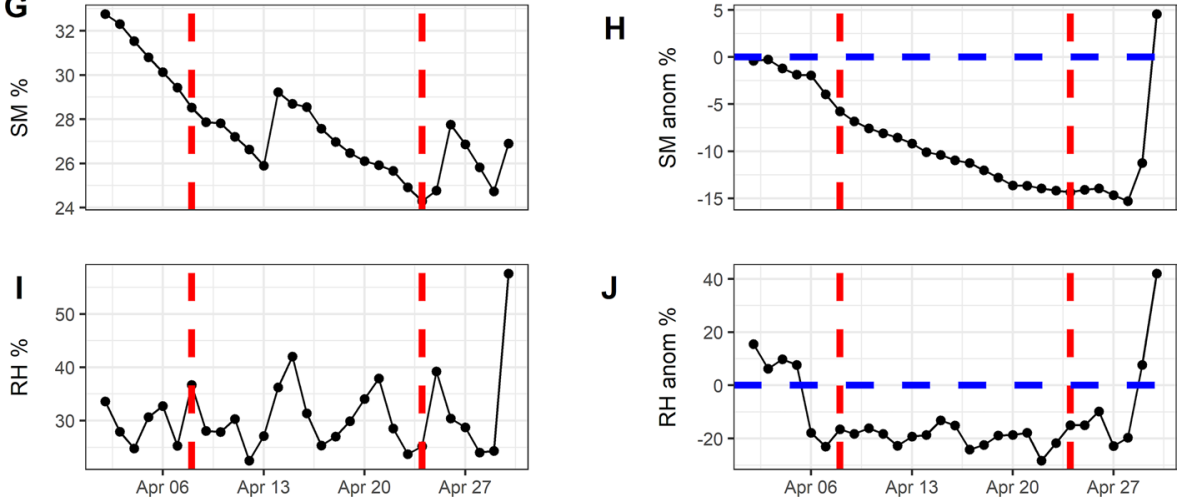

Fig. 6 Weather conditions for the CEZ in the days preceding, during and after the CPPF, for precipitation, temperature, wind speed, soil moisture and relative humidity. Dashed red lines mark the start and end dates of the CPPF. Dashed blue lines (B-J) highlight the 0 line, with values above this line showing positive anomalies and values below showing negative anomalies

The CPPF was unprecedented both in terms of the area burned and also in terms of its close proximity to the Chernobyl reactor and its location in terms of the high concentration of soil ${ }^{137} \mathrm{Cs}$ in this part of the CEZ. Large areas within the CPPF perimeter experienced moderate to high severity burning (Fig. 7a) which can be attributed to the formation of "fuel ladders" in unmanaged forests (see Evangeliou et al. 2015) that can lead to crown fires and the most severe burning. Some clusters of high severity burn are located towards the centre of the fire (Fig. 7b), which tends to be the area that is most difficult to access due to the intensity of the burn posing a high risk to firefighting personnel (DushaGudym 2005; Evangeliou et al. 2015). Unlike previous wildfires in the CEZ, the physical footprint of the fire was in extremely close proximity to the Chernobyl reactor. Whilst the recent installation of a $€ 1.5$-billion New Safe Confinement structure should protect the 


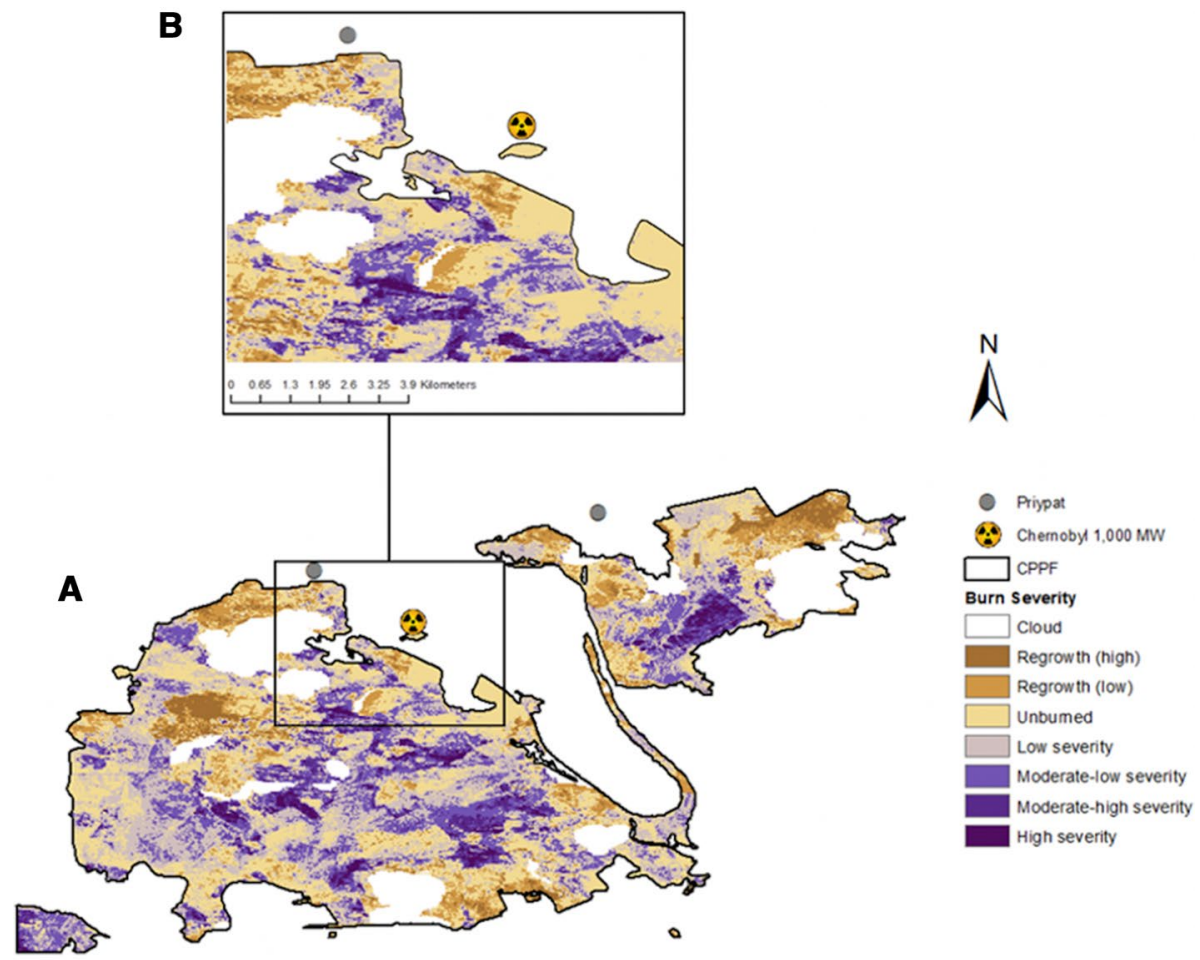

$\begin{array}{lllllll}0 & 1.5 & 3 & 4.5 & 6 & 7.5 & 9 \text { Kilometers }\end{array}$

Fig. 7 a The entirety of the area affected by the CPPF wildfire and the spatial variation of burn severity; b a close-up of the burn severity in areas of close proximity to the Chernobyl reactor and Prip'yat (west)

reactors remains (Chircui 2020; Shylenko 2020), it is nevertheless important that this area be protected from fire. Containment of the CPPF has been partly attributed to the arrival of rainfall across the Kiev Oblast (Pavlovska 2020; Mack 2020). Without this rainfall, it is possible the area of high severity burning would have continued to spread up to and engulfing the area around the reactor, which contains a higher proportion of the area's radionuclides, alongside waste storage facilities originating from when the plant was still in use. Thus, had this area been completely consumed by the fire, the atmospheric dispersal of ${ }^{137} \mathrm{Cs}$ would have been significantly enhanced, indicating that more management is needed to ensure that this does not occur. Relying on potential precipitation events to quench the flames, in particular due to clear evidence low precipitation anomalies are becoming more common (Fig. 4), could lead to a catastrophic scenario.

Our estimate of $3854 \mathrm{GBq}$ of ${ }^{137} \mathrm{Cs}$ resuspended during the CPPF is considerably lower than the estimate of $10,900 \mathrm{GBq}$ for two fires in 2015 that burned $108 \mathrm{~km}^{2}$ (Evangeliou et al. 2016). Conversely, our estimate is an order of magnitude higher than the estimate of $341 \mathrm{GBq}$ for the entire April 2020 wildfire complex (Evangeliou and Eckhardt 2020), although this difference can be attributed to methodological differences concerning the approaches used to estimate emissions, all of which have considerable uncertainty associated with them. A validation of atmospheric concentrations of ${ }^{137} \mathrm{Cs}$ in the Evangeliou 


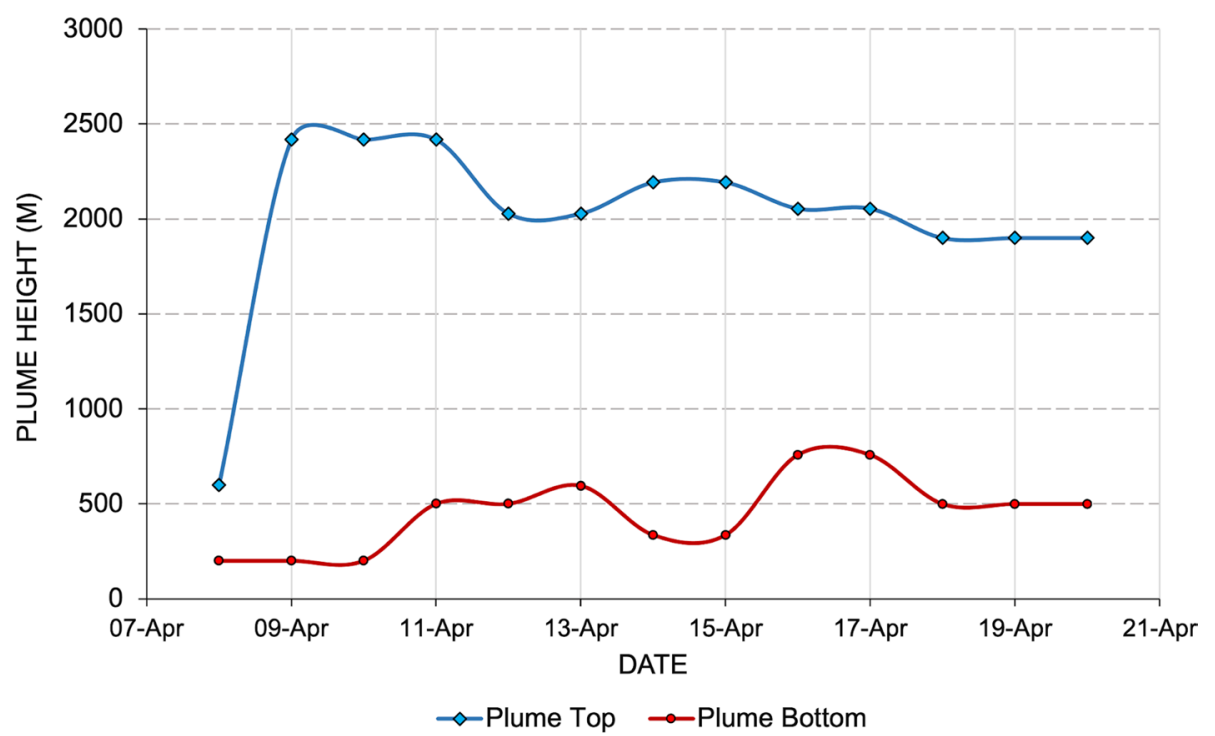

Fig. 8 Height of the CPPF smoke plume. Data obtained from the Copernicus Atmospheric Monitoring Service Information Global Fire Assimilation (CAMS GFAS 2020) database

and Eckhardt (2020) found that modelled concentrations were underestimated compared with ground-based measurements across Europe, which they state maybe due in part to an underestimation of the proportion of ${ }^{137} \mathrm{Cs}$ that is resuspended.

HYSPLIT model results showed that the atmospheric transport and subsequent deposition of ${ }^{137} \mathrm{Cs}$ that was resuspended by the wildfire was transported over a vast area, northwards up to the Arctic Circle, and southwards to northern Africa. Stoulos et al (2020) reported slightly elevated atmospheric concentrations of ${ }^{137} \mathrm{Cs}$ in northern Greece, between 11 and 13 April, due to an intensification of the wildfire as it progressed, and the height at which the air masses were travelling towards this region (between 1500 and $2000 \mathrm{~m}$ ). These elevated concentrations were captured in the footprint of ${ }^{137} \mathrm{Cs}$ concentrations modelled by HYSPLIT (Fig. 9). Whilst the amount of ${ }^{137} \mathrm{Cs}$ suspended within the atmosphere can pose a risk due to inhalation of contaminated air (Ager et al. 2019) and the dispersal of ${ }^{137} \mathrm{Cs}$ occurred over a vast area of eastern Europe and western Asia, these atmospheric concentrations were generally low and are therefore likely to have posed negligible risk. In terms of the deposition of ${ }^{137} \mathrm{Cs}$, other than in the area in very close proximity to the southern part of the CEZ where deposition values reached greater than $10 \mathrm{~Bq} \mathrm{~m}^{2}$ (Fig. 10), deposition values were very low, mostly between 0.0001 and $1 \mathrm{~Bq} \mathrm{~m}{ }^{2}$. These patterns of deposition are comparable with those found by Evangeliou and Eckhardt (2020). Deposition levels reported here are in the same range as those reported by Evangeliou et al (2016) for the CPR and are unlikely to translate into hazardous amounts for those living in the worst affected areas. For example, the 2015 wildfires were expected to have exposed those in close proximity to radiation levels below that of a medical chest X-ray $(0.02 \mathrm{mSv})$ and skull X-ray (0.06 mSv) when deposition levels were converted into effective doses (Evangeliou et al. 2016). As levels approximated by our modelling are within the same range of those produced in this paper, this comparison against medical procedures is useful to augment the conclusion the resuspension of ${ }^{137} \mathrm{Cs}$ from the CPPF event poses no public health risk. 
A $8^{\text {th }}$ April

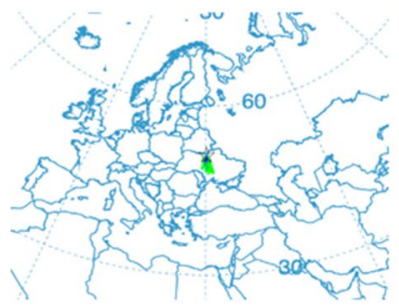

D $11^{\text {th }}$ April

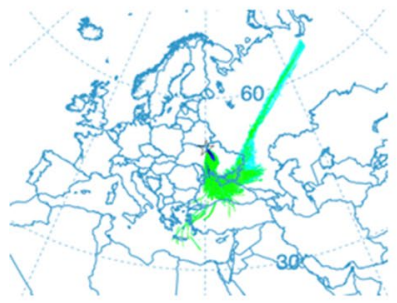

G $14^{\text {th }}$ April

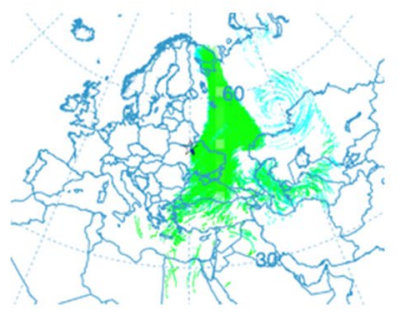

$\mathrm{J} 17^{\text {th }}$ April

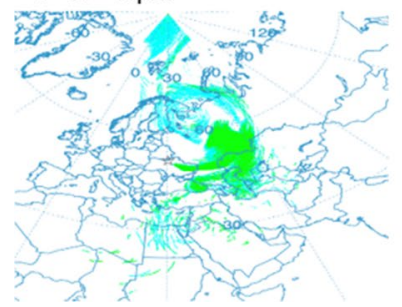

B $9^{\text {th }}$ April

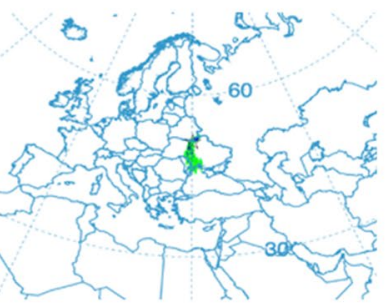

E $12^{\text {th }}$ April

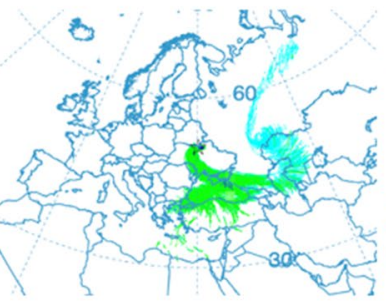

H $15^{\text {th }}$ April

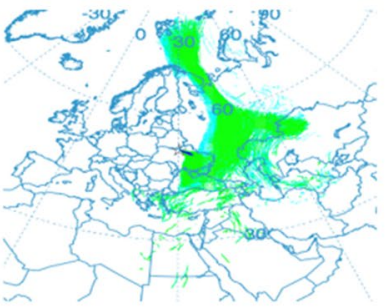

K $18^{\text {th }}$ April

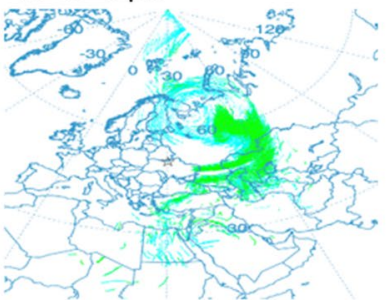

C $10^{\text {th }}$ April

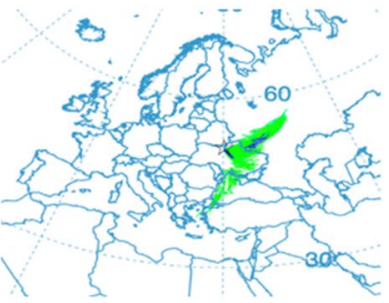

F $13^{\text {th }}$ April

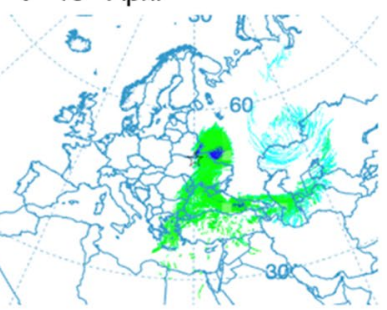

\section{I $16^{\text {th }}$ April}
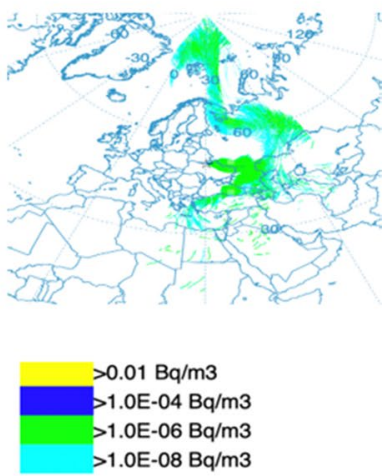

Maximum: $1.4 \mathrm{E}-03 \mathrm{~Bq} / \mathrm{m} 3$

Minimum: $7.5 \mathrm{E}-17 \mathrm{~Bq} / \mathrm{m} 3$

Fig. $9{ }^{137} \mathrm{Cs}$ concentrations within the atmosphere between 8 April 2020 and 18 April 2020 originating from the CPPF event

At the scale of the individual CPPF wildfire, the resuspension and subsequent deposition of ${ }^{137} \mathrm{Cs}$ does not translate into hazardous amounts. However, during April 2020, a further $196 \mathrm{~km}^{2}$ of the CEZ also burned, and so the overall dispersal of ${ }^{137} \mathrm{Cs}$ for this time period, from the entire wildfire complex, will be higher than the values reported here.

Wildfires drive radionuclide resuspension via the combustion of upper soil layers and vegetation, and subsequent dispersal via atmospheric processes, as described here and elsewhere. However, another pertinent issue that has only recently started to receive attention in relation to the CEZ (Igarashi et al. 2020), is wildfire-driven increases in runoff and soil erosion. Hydrological processes are already considered to be one of the 


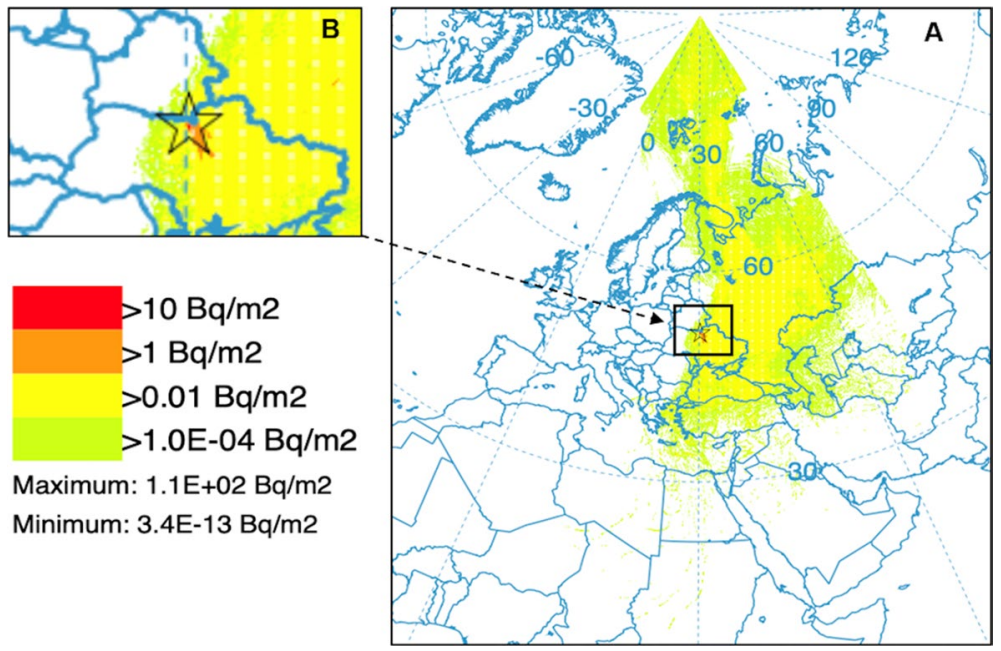

Fig. 10 Total deposition of ${ }^{137} \mathrm{Cs}$ following the CPPF showing the entirety of the countries affected by deposition of ${ }^{137} \mathrm{Cs}$ originating from the CPPF alongside the area affected by the highest deposition values

major drivers of post-depositional radionuclide redistribution (Smith et al. 2004), irrespective of wildfire. It is well established that fire can enhance soil repellency, increased runoff and increased soil erosion (Certini 2005; Ebel et al. 2012; Robichaud et al. 2016; Cole et al. 2020). Therefore, there is the potential for wildfires to result in compound hazard effects, whereby they not only increase atmospheric dispersal of radionuclides, but also drive increases in hydrologically driven radionuclide dispersal within the hydrological system. Runoff generated within the CEZ flows into the main Prip'yat river, which is a critical component of the Dnieper river reservoir system. The Dnieper system is one of the largest surface water systems in Europe (IAEA 2006), and through this river system, there is potential for radionuclides to be transported into the Kiev metropolitan area (Igarashi et al. 2020). Therefore, understanding how surface runoff and soil erosion within the CEZ may impact downstream ecosystems is critical.

Past research within the CEZ has shown that the combustion of the top layer of soil is commonly associated with wildfire events, which results in the destruction of the top elements of soil (Dusha-Gudym 2005), rendering the soil more susceptible to erosion. In a series of plot-scale studies within the CEZ, Igarashi et al (2020) observed dissolved and particulate ${ }^{137} \mathrm{Cs}$ fluxes of 4.9 and $160.9 \mathrm{~Bq} \mathrm{~m}^{2}$, respectively, on a previously burned site for a $286 \mathrm{~mm}$ rainfall event, compared with dissolved and particulate fluxes of 6.22 and $8.63 \mathrm{~Bq} \mathrm{~m}^{2}$ at an unburned site for a $182 \mathrm{~mm}$ rainfall event. Their results indicate that wildfires do not cause increases in the dissolved ${ }^{137} \mathrm{Cs}$ fluxes, but do result in a significant increase in the erosion-driven particulate flux.

Thus, it is clear that a very important coupling between wildfire activity and runoff and erosion processes is likely to persist in the CEZ. This coupling has the potential to affect radionuclide dispersal to a greater extent than is reported in this study, and other recent studies (e.g. Ager et al. 2019; Evangeliou and Eckhardt 2020) that have only considered wildfire-driven atmospheric dispersal, and requires further study, especially given the increase in extreme wildfires. 


\section{Conclusion}

Analysis of the historical wildfire record for the CEZ shows an overall trend of increasing wildfire burn area, which has a strong association with the extreme temperature, relative humidity and soil moisture anomalies that contribute to fuel aridity. HYSPLIT modelling results have shown that a single wildfire does not present a hazard in terms of the resuspension and subsequent atmospheric dispersal of ${ }^{137} \mathrm{Cs}$. However, the increasing frequency of "unprecedented" wildfires, alongside the likely coupling between wildfire and runoffdriven redistribution of particulate ${ }^{137} \mathrm{Cs}$ may lead to compound effects over both time and space (Bondar et al. 2014). Thus, ultimately the deposition of ${ }^{137} \mathrm{Cs}$ in downwind areas may potentially reach harmful concentrations, impacting food chains and increasing the likelihood of water supply contamination (Zibstev et al. 2011; Bondar et al. 2014).

Supplementary Information The online version contains supplementary material available at https://doi. org/10.1007/s11069-021-04902-7.

Acknowledgements The authors gratefully acknowledge the NOAA Air Resources Laboratory (ARL) for the provision of the HYSPLIT transport and dispersion model and READY website (https://www.ready. noaa.gov) used in this publication.

Funding None.

Availability of data and materials All data used in this manuscript are publically available, as detailed in methods.

Conflict of interest The authors declare that they have no conflict of interest.

Open Access This article is licensed under a Creative Commons Attribution 4.0 International License, which permits use, sharing, adaptation, distribution and reproduction in any medium or format, as long as you give appropriate credit to the original author(s) and the source, provide a link to the Creative Commons licence, and indicate if changes were made. The images or other third party material in this article are included in the article's Creative Commons licence, unless indicated otherwise in a credit line to the material. If material is not included in the article's Creative Commons licence and your intended use is not permitted by statutory regulation or exceeds the permitted use, you will need to obtain permission directly from the copyright holder. To view a copy of this licence, visit http://creativecommons.org/licenses/by/4.0/.

\section{References}

Abatzoglou JT, Williams AP (2016) Impact of anthropogenic climate change on wildfire across western US forests. Proc Natl Acad Sci 113:11770-11775. https://doi.org/10.1073/pnas.1607171113

Ager A, Lasko R, Myroniuk V, Zibtsev S, Day M, Usenia U, Bogomolov V, Kovalets I, Evers C (2019) The wildfire problem in areas contaminated by the Chernobyl disaster. Sci Total Environ 696:133954. https://doi.org/10.1016/j.scitotenv.2019.133954

Alimov R (2020) Chernobyl still burns. Greenpeace. https://www.greenpeace.org/international/story/30198/ chernobyl-still-burns-forest-fires-ukraine-nuclear-radiation/. Accessed 1 May 2021

Amiro B, Sheppard S, Johnston F, Evenden W, Harris D (1996) Burning radionuclide question: What happens to iodine, cesium and chlorine in biomass fires? Sci Total Environ 187(2):93-103. https://doi.org/ 10.1016/0048-9697(96)05125-X

Balabukh V, Malystka L (2017) Impact of climate change on natural fire danger in Ukraine. Idoejaras. 121(4):453-477

Benscoter B, Thompson D, Waddington J, Flannigan M, Wotton B, de Groot W, Turetsky M (2011) Interactive effects of vegetation, soil moisture and bulk density on depth of burning of thick organic soils. Int J Wildl Fire 20(3):418-429. https://doi.org/10.1071/WF08183 
Bondar Y, Navumau A, Nikitin A, Brown J, Dowdall M (2014) Model assessment of additional contamination of water bodies as a result of wildfires in the Chernobyl exclusion zone. J Environ Radioact 138:170-176. https://doi.org/10.1016/j.jenvrad.2014.08.018

Borsuk O, Zibstev S (2013) Fire History in Mountain Forests of the Crimean Peninsula of Ukraine. In: International Caucasian Forestry Symposium 24th-26th October, Turkey

Brown J, Bondar Y, Kashparov V, Nalbandyan A, Navumav A, Skipperud L, Sokolik G, Strand P, Zhukova O (2011) Radioactive contamination in the Belarusian sector of the Chernobyl Exclusion Zone. Radioprotection 46(6):771-777. https://doi.org/10.1051/radiopro/20116948s

CAMS GFAS (2020) CAMS Global Fire Assimilation Service Copernicus Climate Change Service. Accessed 1 June 2020

Certini G (2005) Effects of fire on properties of forest soils: a review. Oecologia 143:1-10. https://doi.org/ 10.1007/s00442-004-1788-8

Chaparro D, Vall-llossera M, Piles M, Camp A, Rudiger C, Riere-Tatche R (2016) Predicting the extent of wildfires using remotely sensed soil moisture and temperature trends. IEEE J Sel Top Appl Earth Obs Remote Sens. https://doi.org/10.1109/JSTARS.2016.2571838

Chirciu D (2020) Wildfire no risk to Chernobyl nuclear plant: Zelensky. Anadolu Agency. https://www. aa.com.tr/en/environment/wildfire-no-risk-to-chernobyl-nuclear-plant-zelensky/1805224. Accessed 10 May 2020

Chornokondratenko M, Marrow A (2020) Fire raging near Ukraine's Chernobyl poses radiation risk, say activists. Reuters. https://uk.reuters.com/article/us-ukraine-chernobyl-fire-idUKKCN21V1QW. Accessed 1 May 2020

Cole RP, Bladon KD, Wagenbrenner JW, Coe DBR (2020) Hillslope sediment production after wildfire and post-fire forest management in northern California. Hydrol Process. https://doi.org/10.1002/hyp.13932

Copernicus Climate Change Service (C3S) (2020) C3S ERA5-Land reanalysis' Copernicus Climate Change Service. Accessed 23 May 2020

Copernicus Emergency Management Service-Mapping, (2020) EMSR435: Fire in Chernobyl, Ukraine. https://emergency.copernicus.eu/mapping/list-of-components/EMSR435/ALL/ALL Accessed 5 May 2020

Crimmins MA, Comrie AC (2004) Interactions between antecedent climate and wildfire variability across south-eastern Arizona. Int J Wildl Fire 13(4):455-466. https://doi.org/10.1071/WF03064

Dusha-Gudym S (2005) Transport of radioactive materials by wildland fires in the Chernobyl Accident Zone: how to address the problem. Int for Fire News 32:119-125

Ebel BA, Moody JA, Martin DA (2012) Hydrologic conditions controlling runoff generation immediately after wildfire. Water Resour Res 48:03529. https://doi.org/10.1029/2011WR011470Cita

Evangeliou N, Eckhardt S (2020) Uncovering transport, deposition and impact of radionuclides released after the early spring 2020 wildfires in the Chernobyl Exclusion Zone. Sci Rep 10:10655. https://doi. org/10.1038/s41598-020-67620-3

Evangeliou N, Balkanski Y, Cozic A, Hao W, Moller A (2014) Wildfires in Chernobyl-contaminated forests and risks to the population and the environment: A new nuclear disaster about to happen? Environ Int 73:346-358. https://doi.org/10.1016/j.envint.2014.08.012

Evangeliou N, Balkanski Y, Cozic A, Hao W, Mouillot F, Thonicke K, Paugam R, Zibtsev S, Mousseau T, Wang R, Poulter B, Petkov A, Yue C, Cadule P, Koffi B, Kaiser J, Møller A (2015) Fire evolution in the radioactive forests of Ukraine and Belarus: future risks for the population and the environment. Ecol Monogr 85(1):49-72. https://doi.org/10.1890/14-1227.1

Evangeliou N, Zibtsev S, Myroniuk V, Zhurba M, Hamburger T, Stohl A, Balkanski Y, Paugam R, Mousseau T, Møller A, Kireev S (2016) Resuspension and atmospheric transport of radionuclides due to wildfires near the Chernobyl Nuclear Power Plant in 2015: an impact assessment. Sci Rep. https://doi. org/10.1038/srep26062

Freitas SR, Longo KM, Chatfield R, Latham D, Silva Dias MAF, Andreae MO, Prins E, Santos JC, Gielow R, Carvalho JA Jr (2007) Including the sub- grid scale plume rise of vegetation fires in low resolution atmospheric transport models. Atmos Chem Phys 7:3385-3398. https://doi.org/10.5194/ acp-7-3385-2007

Hao WM et al (2018) Cesium emissions from laboratory fires. J Air Waste Manag Assoc 68:1211-1223. https://doi.org/10.1080/10962247.2018.1493001

Hijmans RJ, van Etten J (2012) raster: Geographic analysis and modeling with raster data. R package version 2.0-12. http://CRAN.R-project.org/package=raster

Hohl A, Niccolai A, Oliver C, Melnychuk D, Zibstev S, Goldammer J, Gulidov V (2012) The human health effects of radioactive smoke from a catastrophic wildfire in the Chernobyl Exclusion Zone: a worst case scenario. J Earth Bioresour Life Qual 1:1-34 
Holden ZA, Swanson A, Luce CH, Jolly WM, Maneta M, Oyler JW, Warren DA, Parsons R, Affleck D (2018) Decreasing fire season precipitation increased recent western US forest wildfire activity. Proc Natl Acad Sci USA 115:8349-8357. https://doi.org/10.1073/pnas.1802316115

IAEA: International Atomic Energy Agency (2006) [Radioactivity in the Dnieper River Basin] Radiological Conditions in the Dnieper River Basin, Assessment by an international expert team and recommendations for an action plan. Radiological Assessment Reports Series 15-20. IAEA, Vienna, 2006

Igarashi Y, Onda Y, Wakiyama Y, Konoplev A, Zheleznyak M, Lisovyi H, Laptev G, Damiyanovich V, Samoilov D, Nanba K, Kirieiev S (2020) Impact of wildfire on ${ }^{137} \mathrm{Cs}$ and ${ }^{90} \mathrm{Sr}$ wash-off in heavily contaminated forests in the Chernobyl exclusion zone. Environ Pollut 259:11376. https://doi.org/10. 1016/j.envpol.2019.113764

Kaiser J, Heil A, Andreae M, Beneditti A, Chubarova N, Jones L, Morcrette J, Razinger M, Schultz M, Suttie M, van der Werf G (2012) Biomass burning emissions estimated with a global fire assimilation system based on observed fire radiative power. Biogeosciences 9:527-554. https://doi.org/10.5194/ bg-9-527-2012

Kashparov V, Levchuk S, Zhurba M, Protsak V, Khomutinin Yu, Beresford NA, Chaplow JS (2017) Spatial datasets of radionuclide contamination in the Ukrainian Chernobyl Exclusion Zone. NERC Environmental Information Data Centre

Kauffman J (2004) Death Rides the forest: perceptions of fire, land use, and ecological restoration of western forests. Conserv Biol 18(4):878-882. https://doi.org/10.1111/j.1523-1739.2004.545_1

Keeley J, Fotheringham C, Moritz M (2004) Lessons from the October 2003 Wildfires in Southern California. J for Res 102(7):26-32. https://doi.org/10.1093/jof/102.7.26

Key C, Bensen N (2006) Landscape assessment-sampling and analysis methods. USDA Forest Service General Technical Report RMS-GTR-164-CD

Krivoruchko K, Gribov A (2020) Empirical Bayesian kriging implementation and usage. Sci Total Environ. https://doi.org/10.1016/j.scitotenv.2020.137290

Krueger E, Ochsner T, Carlson J, Engle D, Twidwell D, Fuhlendorf S (2016) Concurrent and antecedent soil moisture relate positively or negatively to probability of large wildfires depending on season. Int J Wildl Fire 25(6):657-668. https://doi.org/10.1071/WF15104

Mack E (2020) Chernobyl Fires Drop Radioactive Ash, Sending Air Quality Plummeting. Forbes. https:// www.forbes.com/sites/ericmack/2020/04/17/chernobyl-fires-drop-radioactive-ash-send-air-qualityplummeting/\#49bf79e274dc. Accessed 1 May 2020

Nelson D, Chen Y, Kahn R, Diner D, Mazzoni D (2008) Example applications of the MISR INteractive eXplorer (MINX) software tool to wildfire smoke plume analyses. Remote Sens. https://doi.org/10. $1117 / 12.795087$

Nelson D, Garay M, Kahn R, Dunst B (2013) Stereoscopic height and wind retrievals for aerosol plumes with the MISR INteractive eXplorer (MINX). Remote Sens 5(9):4593-4628. https://doi.org/10.3390/ rs5094593

Paatero J, Vesterbacka K, Makkonen U, Kyllonen K, Hellen H, Hatakka J, Antilla P (2009) Resuspension of radionuclides into the atmosphere due to forest fires. J Radioanal Nucl Chem 282(2):473-476. https:// doi.org/10.1007/s10967-009-0254-9

Paliourious G, Taylor H, Wein R, Svoboda J, Mierzynski B (1995) Fire as an agent in redistributing fallout ${ }^{137} \mathrm{Cs}$ in the Canadian boreal forest. Sci Total Environ 160-161:153-166. https://doi.org/10.1016/00489697(95)04353-3

Paller M, Jannik G, Baker R (2014) Effective half-life of Caesium-137 in various environmental media at the Savannah river site. J Environ Radioact 131:81-88. https://doi.org/10.1016/j.jenvrad.2013.10.024

Pavlovska E (2020) New wildfires spread around Chernobyl nuclear plant. NewEurope. https://www.neweu rope.eu/article/new-wildfires-spread-around-chernobyl-nuclear-plant/. Accessed 5 May 2020

Reevell P (2020) Drone video shows devastation caused by wildfires across Chernobyl. abc News https:// abcnews.go.com/International/drone-video-shows-devastation-caused-wildfires-chernobyl/story?id= 70363555. Accessed 5 May 2020

Remy S, Veira A, Paugam R, Sofiev M, Kaiser J et al (2017) Two global data sets of daily fire emission injection heights since 2003. Atmos Chem Phys 17(4):2921-2942. https://doi.org/10.5194/ acp-17-2921-2017

Robichaud PR, Wagenbrenner JW, Pierson FB, Spaeth KE, Ashmun LE, Moffet CA (2016) Infiltration and interrill erosion rates after a wildfire in western Montana. USA Catena 142:77-88

Rolph G, Stein A, Stunder B (2017) Real-time environmental applications and display system: READY. Environ Modell Softw 95:210-228. https://doi.org/10.1016/j.envsoft.2017.06.025

Roth A (2020) Ukraine: wildfires draw dangerously close to Chernobyl site. The Guardian. https://www. theguardian.com/environment/2020/apr/13/ukraine-wildfires-close-chernobyl-nuclear-site. Accessed 25 June 2020 
Samsanova V, Blagoveshchenskii Y, Meshalkina Y (2017) Use of empirical Bayesian kriging for revealing heterogeneities in the distribution of organic carbon on agricultural lands. Eurasian Soil Sci 50:305311. https://doi.org/10.1134/S1064229317030103

Shylenko O (2020) Fires in Chernobyl Exclusion Zone are still getting closer to the reactor. ScienceAlert. https://www.sciencealert.com/fires-in-chernobyl-exclusion-zone-have-now-reached-the-ghost-town-ofpripyat Accessed 5 May 2020

Skrynyk O, Voloshuk V, Budak I, Bubin S (2019) Regional HYSPLIT simulation of atmospheric transport and deposition of the Chernobyl ${ }^{137}$ Cs releases. Atmos Pollut Res 10(6):1953-1963. https://doi.org/10. 1016/j.apr.2019.09.001

Smith JT, Wright SM, Cross MA, Monte L, Kudelsky AV, Saxen R, Vakulovsky SM, Timms DN (2004) Global Analysis of the riverine transport of ${ }^{90} \mathrm{Sr}$ and ${ }^{137} \mathrm{Cs}$. Environ Sci Technol 38:850-857. https:// doi.org/10.1021/es0300463

Soverel N, Perrakis D, Coops N (2010) Estimating burn severity from Landsat dNBR and RdNBR indices across western Canada. Remote Sens Environ 114(9):1896-1909. https://doi.org/10.1016/j.rse.2010. 03.013

Stein AF, Draxler RR, Rolph GD, Stunder BJB, Cohen MD, Ngan F (2015) NOAA's HYSPLIT atmospheric transport and dispersion modeling system. Bull Am Meteorol Soc 96:2059-2077. https://doi.org/10. 1175/BAMS-D-14-00110.1

Stoulos S, Besis A, Ioannidou A (2020) Determination of low ${ }^{137}$ Cs concentration in the atmosphere due to Chernobyl contaminated forest-wood burning. J Environ Radioact 222:106383. https://doi.org/10. 1016/j.jenvrad.2020.106383

Sungmin O, Hou X, Orth R (2020) Observational evidence of wildfire-promoting soil moisture anomalies. Sci Rep 10:11008. https://doi.org/10.1038/s41598-020-67530-4

Van Wagner CE (1987) Development and Structure of the Canadian Forest Fire Weather Index System. Canadian Forestry Service, Headquarters, Ottawa. Forestry Technical Report 35

Westerling AL, Hidalgo HG, Cayan DR, Swetnam TW (2006) Warming and earlier spring increase western US forest wildfire activity. Science 313:940-943. https://doi.org/10.1126/science.1128834

Yablokov AV, Nesterenko V, Nesterenko A (2009) Chernobyl: consequences of the catastrophe for people and nature. New York Academy of Sciences, New York, USA.

Yankasova G, Hannam K (2013) Dark and toxic tourism in the Chernobyl Exclusion Zone. Curr Issues Tour 17(1):929-939. https://doi.org/10.1080/13683500.2013.820260

Yoschenko V, Kashparov V, Protsak V, Lundin S, Levchuk S, Kadygrib A, Zvarich S, Khomutinin Y, Maloshtan I, Lanshin V, Kovtun M, Tschiersch J (2006) Resuspension and redistribution of radionuclides during grassland and forest fires in the Chernobyl exclusion zone: part I fire experiments. J Environ Radioact 86(2):143-163. https://doi.org/10.1016/j.jenvrad.2005.08.003

Zibstev S, Oliver C, Goldammer J, Hohl A, McCarter J, Niccolai A, Petrenko M, Borsuk O (2011) Wildfires Risk Reduction From Forests Contaminated by Radionuclides: A Case Study of the Chernobyl Nuclear Power Plant Exclusion Zone. The 5th international Wildfire Conference, South Africa

Publisher's Note Springer Nature remains neutral with regard to jurisdictional claims in published maps and institutional affiliations. 